Revta bras. Zool.,

\title{
MUSEUS UNIVERSITĀRIOS
}

Ubirajara R. Martins ${ }^{1}$

A abrangência do título em epígrafe é muito maior do que à primeira vista possa parecer, embora a nível mundial, relativamente pouquíssimos museus pertençam a Universidades. Minhas limitações obrigam-me a restringir estas notas aos museus zoológicos e aos departamentos universitários onde se ensina Zoologia.

Mencionam-se, superficialmente, os museus do globo e suas relações com universidades e coleções zoológicas universitárias destituídas do rótulo "Museu". Abordam-se também aspectos da integração museu e universidade com ênfase aos departamentos possuidores de coleções.

\section{Museus e universidades no mundo}

As instituições que conservam coleções zoológicas, produzem pesquisa científica com fundamento nesse acêrvo, formam e/ou preparam pessoal especializado e veiculam cultura à população, são das mais variadas naturezas, nem sempre um Museu, embora esses sejam os atributos de um museu moderno. É cer to que muitos museus zoológicos enquadram-se nessas características e como o tema em pauta são os "Museus Universitários", estas notas deveriam cuidar apenas destas instituições e sua vinculação, direta ou indireta, com as universidades.

Entretanto, no nosso país e certamente em muitos outros, a maioria dos núcleos de pesquisa zoológica nas universidades está estabelecida em Departamentos, cujos acêrvos não podem ser rotulados como "Museus". Julgo portanto necessário focalizar também aspectos das coleções e das pesquisas zoológicas nos departamentos de uma universidade, embora não constituam formalmente um museu.

\subsection{Museus Nacionais}

São grandes instituições destinadas a reunir grandes coleções com representatividade internacional e que envolvem várias áreas da Ciência Biológica (Antropologia, Botânica, Paleontologia, Zoologia, etc.).

Praticamente em todo o planeta (cf. "The World of Learning") os museus nacionais não pertencem a nenhuma universidade. Dentre os mais importantes, poderíamos citar, à guiza de exemplo, na Europa Ocidental, o "British Museum

1 Museu de Zoologia - USP, São Paulo-SP. 
Revta bras. Zool.

of Natural History", Londres (fundado em 1753) e o "Museúm National d'Histoire Naturelle", Paris (f. 1635). Na Europa Oriental, o "Národni Muzeum", Praga (f. 1818) e o "Muzeul de Istorie Naturala Grigore Antipa", Bucarest (f. 1830). Na América do Norte, o "National Museum of Natural History", Washington (f. 1846?) e o "National Museum of Natural Sciences", Ottawa (f. 1843), enfim, em toda parte, como o "National Museum", Bloemfontein (f. 1817) ou o "Australian Museum", Sydney (f. 1827).

As exceções que podemos encontrar são o "Moscow State University Museum of Zoology", Moscou (f. 1791) e o "Museum für Naturkunde" da Universidade Humboldt, Berlim (f. 1810). No nosso país, o Museu Nacional, Rio de Janeiro (f. 1818) da Universidade Federal do Rio de Janeiro.

\subsection{Outros grandes museus}

Ainda que destituídos do título de "nacionais", pelo vultoso acêrvo que abrigam e pelo volume de pesquisa zoológica que já produziram, equiparam-se ou mesmo superam os museus ditos nacionais.

Situam-se aquí, independentes de universidades, para exemplificar, os museus da Alemanha Ocidental (Bonn, Frankfurt, München, Stturgart), da Espanha (Barcelona), da Suissa (Basiléia, Genebra), da Itália (Genova), dos Estados Unidos (Chicago, Los Angeles, San Francisco, Nova York, Pittsburgh, Philadelphia), da Holanda (Leiden), e assim por diante, em todas as partes do mundo, às dezenas.

Pertencem a universidades algumas instituições como o "Museum of Comparative Zoology", Universidade de Harvard, Cambridge e o "Hope Museum" da Universidade de Oxford. No Brasil pertencem a universidades o Museu de Zoologia da Universidade de São Paulo e o Museu de Ciências da Pontifícia Universidade Católica do Rio Grande do Sul.

\section{Coleções pertencentes a Institutos, Faculdades ou Departamentos universitários.}

São coleções que embora muito amplas em alguns casos, não têm a denominação específica de "Museu" e mantém-se nas e pelas universidades. Restringindo exemplos às instituições brasileiras, poderia citar o Instituto Oceanográfico, USP; departamentos de universidades federais (UFPR, UFPB, UFRRJ, etc.) ou de universidades estaduais como a UNICAMP e a UNESP.

Do exposto conclui-se que os museus, a nível mundial, muito raramente pertencem a Universidades e que no Brasil, a vinculação predominante entre pesquisa zoológica e universidade é a nível de Departamentos.

\section{Aspectos da integração Museu-Universidade}

\subsection{Museus universitários}

Sob aspecto estritamente zoológico, os museus de toda parte têm colaborado estreitamente com as universidades, principalmente na formação de recursos 
Vol. 5(4), 1988

humanos e especialmente ao nível de pós-graduação. Essa colaboração basicamente se resume no oferecimento de disciplinas por pesquisadores dos museus na universidades, no livre acesso dos pós-graduandos às coleções e bibliotecas para produção de dissertações e teses, expedições conjuntas, convênios educacionais e culturais, etc.

Os exemplos estrangeiros são copiosos: "British Museum - Imperial College - University of London"; "California Academy of Sciences - University of California", e dezenas de outros.

No Brasil, essa colaboração é permanente quer no Museu Nacional, quer no Museu de Zoologia, mas na minha opinião, muito aquém do desejável como adiante se conclui.

\subsection{Coleções zoológicas departamentais}

A nível de departamentos onde se conservam coleções de pesquisa a situação é muito diversa da dos museus universitários. $\mathrm{O}$ docente acumula à função didática (freqüentemente nos cursos de graduação e de pós-graduação), as funções de curadoria e pesquisa.

Já que a função didática, obrigatoriamente, tem que ser exercida, às vezes com carga altíssima, as outras duas funções serão, por conseguinte, prejudicadas: a produção científica é escassa (ou nula) e a curadoria é insuficiente (ou omissa).

Despontam, naturalmente, algumas indagações:

1a. É apropriado que os departamentos consevem coleções de pesquisa, ao lado das didáticas, mesmo após o afastamento, morte ou desinteresse do docente que as reuniu e as estudou?

Parece-me que a solução apropriada seria depositá-las numa instituição apta a preservá-las, ou correríamos o risco de perderem-se acêrvos duramente conseguidos, após anos e anos de sacrifício. Isto porque, num departamento, nem sempre o sucessor de um professor ornitólogo será outro estudioso das aves; poderá, por seleção em concurso, ser um helmintólogo, pouco propenso, por natureza, a curar uma coleção de pássaros.

Por outro lado, estão as instituições para eventual repositório, aptas a receber continuadamente tais acêrvos? Têm pessoal, espaço e recursos disponíveis? No Brasil de maneira geral, neste momento, parece-me que não .

2a. É conveniente que os departamentos, ao lado dos docentes, admitam pessoal do mesmo nível intelectual para curadoria e para pesquisa, com escassa ou nenhuma carga didática?

Assunto polêmico e controvertido, já que muitos docentes considerariam tal pessoal como "previlegiado", pois, ainda que esses professores oferecessem somente disciplinas nos cursos de pós-graduação, suas obrigações escolares seriam muito menores. Por ou tro lado, conservar-se-iam as coleções e a produção científica decorrente do seu estudo, poderia ser muito ampliada.

3a. Já que a grande ênfase, lamentavelmente quase exclusiva, das universidades nos tempos que correm, é a formação de milhares de estudantes a nível de graduação, a falta de docentes em Zoologia, vastíssimo campo, para atender essa formação é conspícua. Seria viável encorajar os docentes para a execução 
Revta bras. Zool.

de novas e árduas tarefas como a curadoria das coleções? Estariam êles dispostos, aptos e com disponibilidade de tempo para aceitar mais responsabilidades?

Uma vez que o pessoal existente nos departamentos é insuficiente para aulas, independentemente das funções de pesquisa e de curadoria, a única solução seria admitir novos docentes para obter-se uma distribuição mais equitativa de tarefas e obrigações. As universidades têm condições materiais e físicas para essas admissões? Desafortunadamente, a resposta parece ser negativa, principalmente na contratação de docentes para as ciências ditas básicas, como a Zoologia, que está "demodé" ao lado da "atualíssima" Biotecnologia, por exemplo.

\subsection{Aspectos administrativos}

Os aspectos administrativos das relações entre museu e universidade e entre departamento e universidades são bastante diversos.

A administração geral, no caso dos museus, representa-se por um diretor; nos departamentos, pelo chefe do departamento. No primeiro caso, a administração poderia ser mais ágil na tomada de decisões, pois elas devem receber sua aprovação apenas por reitorias e, eventualmente, pelos órgãos colegiados superiores. Em suma, o diretor reporta-se diretamente ao reitor. No segundo, as categorias hierárquicas entre um chefe de departamento e uma reitoria são em número muito maior, que vão de conselhos departamentais, passam por chefias de institutos, congregações, até reitorias, pró-reitorias e órgãos colegiados superiores. Ora, tais categorias hierárquicas têm numa universidade, uma enormidade de assuntos, sempre ditos mais urgentes e mais importantes do que aqueles relacionados com "coleções de bichinhos", sua curadoria, sua ampliação ou a admissão de pessoal para cuidá-las. Além disso, a burocracia, a terrível burocracia, cresce, em detrimento da eficiência e da assunção individual de responsabilidades.

Inseridos neste mesmo contexto, poderiam ser discutidos muitos outros problemas inerentes às relações universidade-museu e universidade-departamento, tais como, o provimento de recursos, admissão de pessoal, e assim por diante, já que o procedimento para equacioná-los e resolvê-los segue o mesmo ritual.

\section{Conclusão}

À vista do que acima foi resumidamente exposto, a questão fundamental a responder é esta: é apropriado que as universidades assumam a criação de novos museus e permaneçam responsáveis pelos que já lhes pertencem?

Com vistas ao que ocorre no mundo, a quase totalidade dos Museus não pertence às Universidades mas mantém com elas intercâmbios, convênios, projetos conjuntos, etc.; universidade e museu são órgãos independentes mas suplementares, em mútua colaboração e cooperação, na formação de recursos humanos, na pesquisa, na curadoria dos acêrvos e na difusão da cultura.

No nosso país a experiência tem curta duração e no caso do Museu de Zoologia, particularmente creio que o órgão ainda é estranho à USP. Sua distância física do Campus tem sido apontada como uma das causas. Não concordo. Não me julgo habilitado para discutir a relação Museu Nacional-UFRJ. 
Vol. 5(4), 1988

Outra questão que emerge é a seguinte: no caso dos museus não pertencerem às universidades, onde seriam alocados? Em ministérios, em secretarias de estado, em prefeituras municipais? Nesta hipótese, seus problemas estariam melhor equacionados e solucionados do que no âmbito das universidades?

Fundamentalmente, é preciso que universidades, ministérios ou prefeituras entendam o papel dos museus. A imagem do museu é ainda a do século XIX, isto é, um local onde coisas raras, antigas, valiosas ou exóticas estão armazenadas, sejam pinturas, moedas, animais, plantas, máquinas ou armas. Cumpre a nós, profissionais dos museus, mudar essa imagem. Muito pouca gente sabe que num museu moderno se faz pesquisa, se ensina, se difunde cultura.

Será preciso ter em mente que a Cultura é o alimento do espírito. Mas, senhores, num país onde o alimento para o corpo é insuficiente, é possível priorizar o alimento espiritual? É imperativo que sim, custe o que custar. Um grande povo há que reunir indivíduos sadios, mas obrigatoriamente cultos. 